\title{
The Structural Design of Wooden Solid Log Wall
}

\author{
Petr Kacálek ${ }^{1, *}$, and Tomáš Petř́íček ${ }^{2}$ \\ ${ }^{1}$ Brno University of Technology, Faculty of Civil Engineering, \\ Institute of Building Structures, Veveří 95, 60200 Brno, Czech Republic
}

\begin{abstract}
Alternative solutions to joints of outer wooden solid log walls are based on the current situation on the construction market, which reflects general change in attitude towards the environment. Apart from the evaluation of materials and products in accordance with technological and economic aspects, attention is paid to the effect of individual elements on the environment. This trend is reflected in construction practice by a comeback to original materials and expanding designs of residential buildings on the basis of easily renewable material resources, e.g. wood, which is relatively easily available and renewable construction material. When designing and constructing wooden buildings, it is necessary to take into account specific properties of wood (particularly volume changes), which need to be considered for solutions of individual details. Bed joints of wooden solid log walls are still a problematic detail in terms of thermal technology. It is a contact of two horizontal construction elements beams, where maximum weakening of the wall thickness occurs. This spot is a relatively frequent place of a recurring thermal bridge during the wall construction. Analysis and improvement of this critical place of wooden houses, which has been more and more frequently built in the Czech Republic, would lead to their better evaluation in terms of heat-technical properties. The aim of the project was to design and examine adjusted variants of shape solutions of joints in between individual solid wooden elements. The project particularly focused on monitoring of surface temperatures in the areas of critical details - bed joints.
\end{abstract}

\section{Introduction}

The paper considers a Canadian type wooden solid log wall in terms of thermal technology, while the main goal is to compare variants of design solutions of such wall. Wall models were simulated in software ANSYS.

Due to weakening in the area of bed joints and the heat conductivity coefficient of wood, a solid wooden wall hardly meets current strict requirements of the standard CSN 73 0540-2 [1] for thermal transmittance value U. Therefore, it was particularly the surface temperature, which is one of the evaluation factors of structure quality, which was monitored.

\footnotetext{
*Corresponding author: kacalek.p@,fce.vutbr.cz
} 


\section{Project procedure and solution}

The project was divided into a theory part with modelling of different shapes of joints with different filling materials, and an experimental part when surface temperatures were measured in laboratory conditions. The attention was particularly paid to Canadian type log houses, which are built from hand-made processed logs with the diameter of at least $350 \mathrm{~mm}$.

\section{Experimental measurement}

The experimental part required to create a suitable model of a log wall, where from one side the external environment with reference temperature $-18^{\circ} \mathrm{C}$ was simulated. Subsequently, surface temperatures on the internal surface of the structure were monitored. The built segment of the log wall in the laboratory was made from 5 spruce logs with the diameter of $350 \mathrm{~mm}$ and length of $3.0 \mathrm{~m}$. (Fig. 1,2). Spruce logs were based on asphalt sheets [2,3]. The box, in which the external environment was simulated was built from polystyrene boards of the thickness of $100 \mathrm{~mm}$. External dimensions of the box were: width $2 \mathrm{~m}$, height $1.1 \mathrm{~m}$ and depth $1 \mathrm{~m}$. The box was equipped with an evaporator. The side walls of the box were carved based on the shapes of logs, so that they would fit as close to the log wall as possible. Larger gaps were sealed with a PUR foam and all joints of individual polystyrene boards were sealed with a tape.

The log wall was built with mineral wool insulation applied in bed joints with the profile type 1 (Fig. 3). The joint is a two-stage insulated joint, i.e. the central groove is filled with a heat insulator and memory tapes ILLBRUCK are applied on sides, which are to prevent leakage of air, water and insects into the area of the joint. The experimental measurement does not take into account the effects of the base, atypical details of objects, etc. $[4,5]$

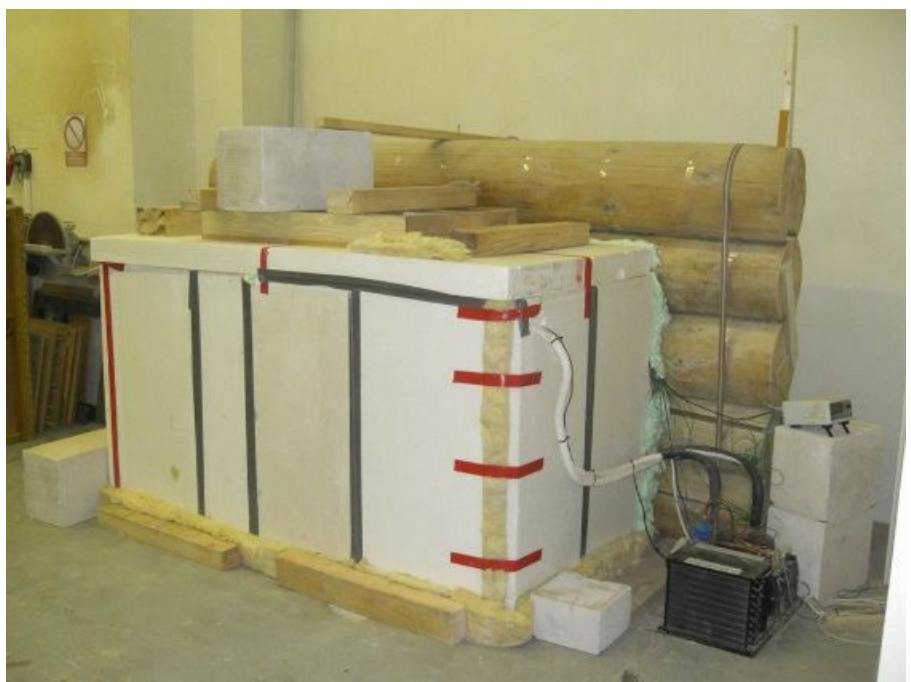

Fig. 1: View of experimental log wall (1) 


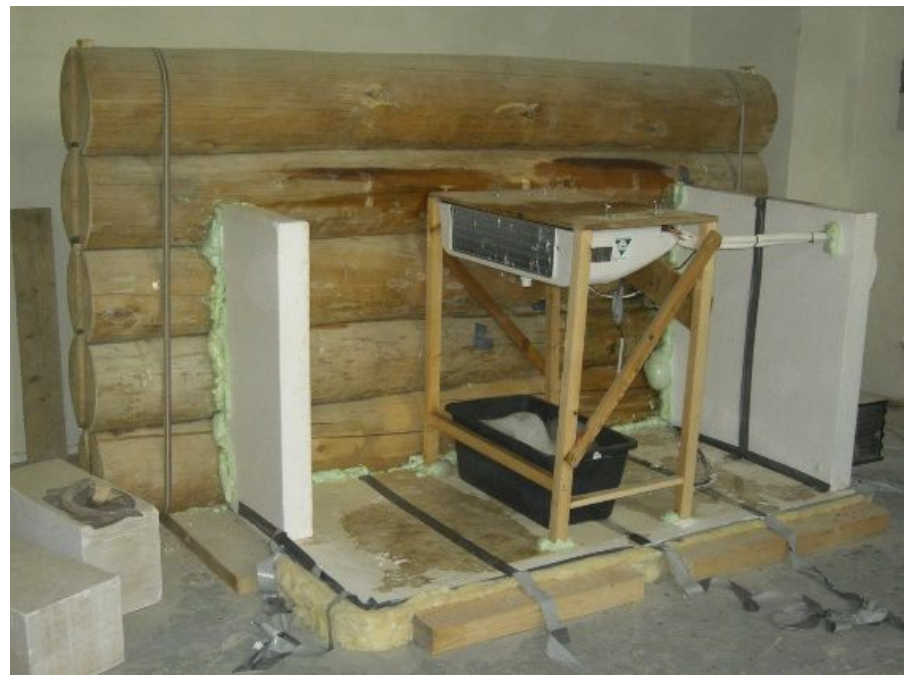

Fig. 2: View of experimental log wall (2)

\section{Theory part}

The theory part of the project was performed with the use of a computing program ANSYS, in which 7 shape variants of the bed joint profile of the log wall were modelled. The joints varied by shape and depth of the groove (Fig. 3). Each type of joint was modelled with four types of heat insulation - assembly PUR foam, mineral wool, fleece, industrial hemp. The result was the evaluation of surface temperatures in the joint and in the maximum width of the wall (on the log surface) on the interior side of the wall. Regarding the joint materials, their suitability and effectiveness were verified in terms of thermal-technological properties as well as in terms of a potential use of permanently renewable natural materials for buildings whose bearing structures are made from solid wood, which is $100 \%$ natural permanently renewable material.

When modelling the log wall, the standard values were used. The following boundary conditions were set: exterior temperature: Te: $-18{ }^{\circ} \mathrm{C}$, interior temperature: Ti: $21^{\circ} \mathrm{C}$

Table 1 shows an overview of all considered materials and their heat insulation properties characterised by the heat conductivity coefficient $\lambda(\mathrm{W} / \mathrm{mK})$. The first table column contains figures of drawings of individual profiles shown in Fig. 3. No.2 shows thermal insulation filling materials of the joint, which differed.

Table 2. Overview of used materials

\begin{tabular}{|c|c|c|}
\hline No. & Material & $\boldsymbol{\lambda}(\mathbf{W} / \mathbf{m K})$ \\
\hline \multirow{3}{*}{2} & Wood - pine & 0.180 \\
\cline { 2 - 3 } 2 & Mineral wood & 0.040 \\
\cline { 2 - 3 } & Fleece & 0.038 \\
\hline \multirow{3}{*}{$\mathbf{2}$} & PUR foam & 0.025 \\
\hline
\end{tabular}



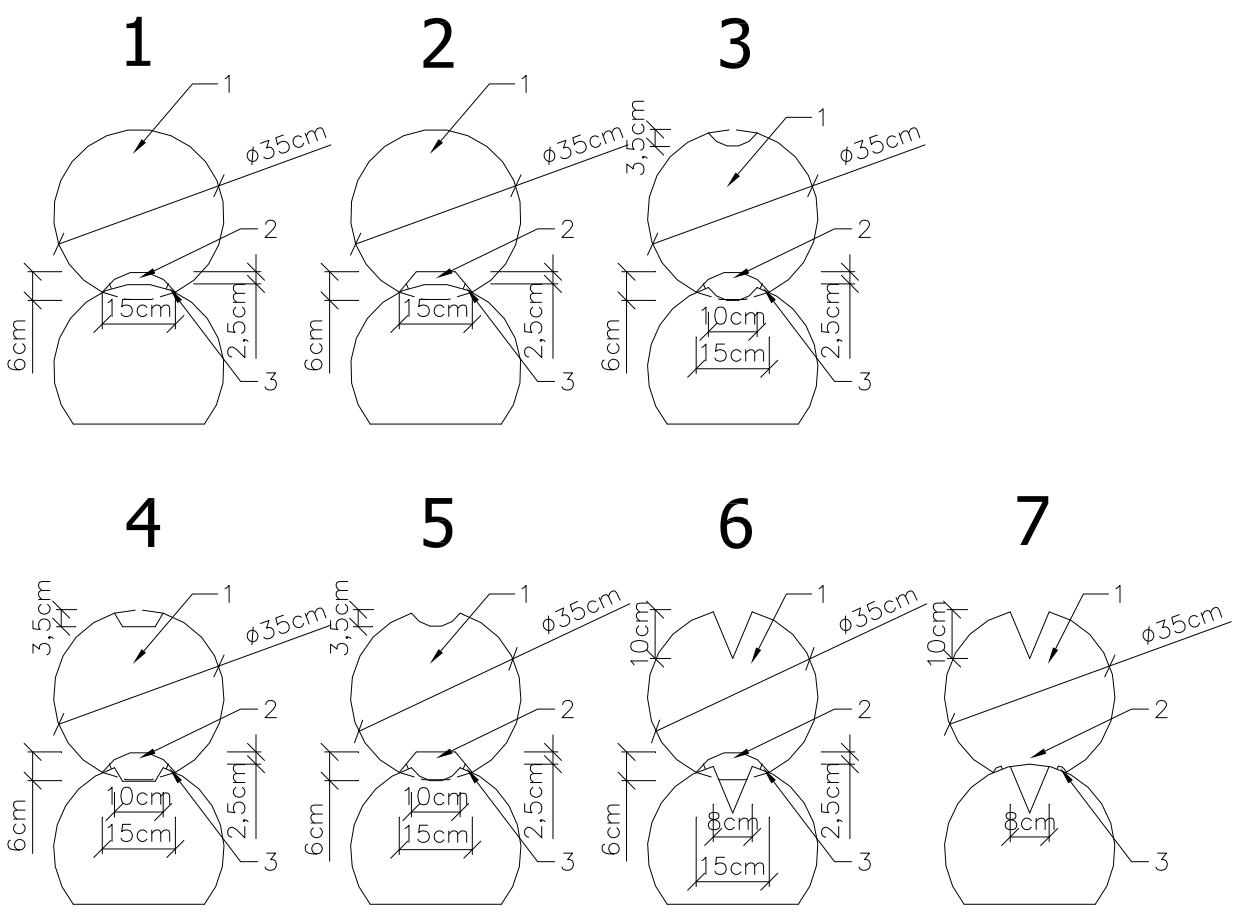

Fig. 3: Overview of modelled types of log wall bed joints

\section{Project results and outcomes}

In program ANSYS a wall was modelled which was later built in the laboratory of Institute of Building Structures. The model of the wall was built from five logs with the diameter of $350 \mathrm{~mm}$, which was adjacent to a box, in which exterior environment temperature Te: $-18{ }^{\circ} \mathrm{C}$ was simulated. Interior temperature was considered at $\mathrm{Ti}: 21{ }^{\circ} \mathrm{C}$. For these boundary conditions, different types of joints were modelled (profile 1 - profile 7 , Fig. 3) with different insulation materials in joints differing in the heat conductivity coefficient (Table 1).

Fig. 4 shows an output from program ANSYS and displays the modelled wall and its cut-out segment, which shows the course of temperatures in the wall structure under constant temperature condition.
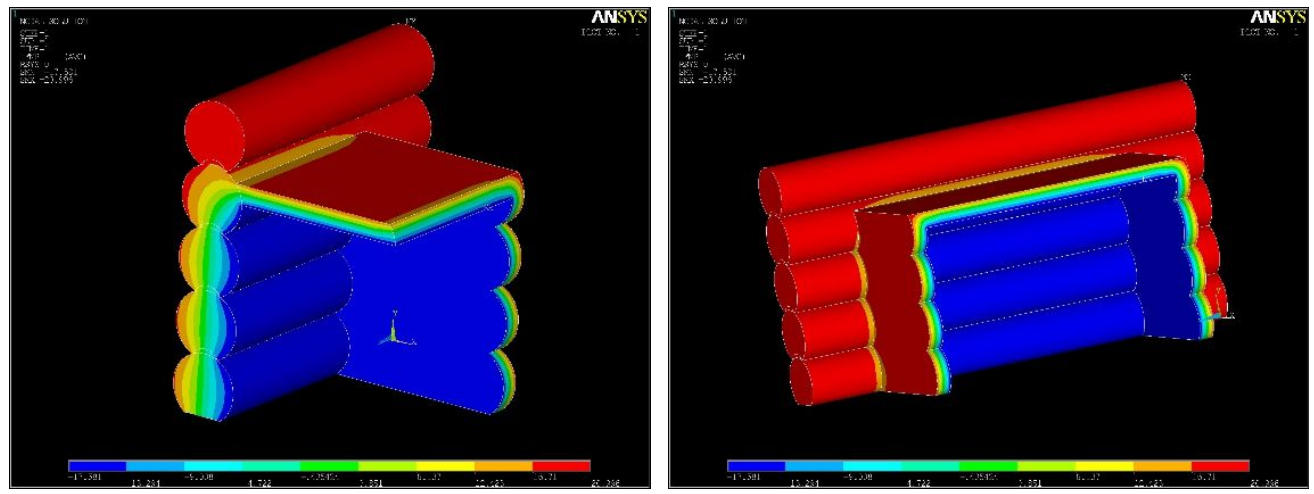

Fig. 4: Laboratory wall model in program ANSYS 
Table 2 shows a selection of measured values of surface temperatures monitored on a model of a log wall in laboratory conditions. It shows values of surface temperatures in the joint and on the log surface for the exterior temperatures in the range of $-18.5^{\circ} \mathrm{C}<\mathrm{Te}<$ $-17.5{ }^{\circ} \mathrm{C}$ as well as interior environment temperatures $20.5{ }^{\circ} \mathrm{C}<\mathrm{Ti}<21.5{ }^{\circ} \mathrm{C}$. The temperatures correspond with the shape profile of the joint No. 1 filled with mineral wool. This type of bed joint is in common use nowadays.

Table 2: Measured data meeting the conditions: $\mathrm{Te}=-18^{\circ} \mathrm{C}, \mathrm{Ti}=21{ }^{\circ} \mathrm{C}$,

\begin{tabular}{|c|c|c|c|c|}
\hline \multirow{4}{*}{} & $\begin{array}{c}\text { Exterior } \\
\text { temperature }\end{array}$ & $\begin{array}{c}\text { Interior } \\
\text { temperature }\end{array}$ & $\begin{array}{c}\text { Surface } \\
\text { temperature of } \\
\text { interior joint }\end{array}$ & $\begin{array}{c}\text { Surface } \\
\text { temperature of } \\
\text { interior log (in } \\
\text { the widest place) }\end{array}$ \\
\hline \multirow{4}{*}{} & & & & \\
\cline { 2 - 5 } & -18.01 & 21.30 & 14.60 & 17.80 \\
\cline { 2 - 5 } & -18.22 & 20.70 & 14.30 & 17.50 \\
\cline { 2 - 5 } & -17.59 & 20.80 & 14.10 & 17.90 \\
\cline { 2 - 5 } & -18.20 & 20.70 & 14.10 & 18.00 \\
\cline { 2 - 5 } & -18.48 & 20.80 & 13.70 & 17.50 \\
\cline { 2 - 5 } & -17.59 & 21.10 & 13.60 & 17.40 \\
\cline { 2 - 5 } & -17.54 & 20.70 & 13.40 & 17.20 \\
\cline { 2 - 5 } & -18.36 & 20.60 & 13.30 & 17.10 \\
\cline { 2 - 5 } & -17.60 & 21.00 & 13.30 & 17.00 \\
\cline { 2 - 5 } & -17.98 & 21.00 & 13.10 & 16.80 \\
\cline { 2 - 5 } & -18.00 & 20.90 & 13.10 & 16.90 \\
\hline \multirow{4}{*}{$\begin{array}{c}\text { Average temperature } \\
\text { values }\end{array}$} & -17.96 & 21.00 & 13.10 & $\mathbf{1 7 . 3 5}$ \\
\hline \multirow{2}{*}{} & -17.76 & 21.10 & 13.60 & \\
\hline
\end{tabular}

Graphic outcomes (Fig. 5) of laboratory measurements show fluctuation of temperature both in the simulated exterior, and interior environment. These temperature fluctuations are caused by the equipment simulating exterior as well as interior environment. However, the graph shows that, based on phase changes of wood, relatively fast fluctuation of ambient temperature has no effect on the monitored values of temperatures in the joint and on the $\log$ surface from the interior side of the wall.

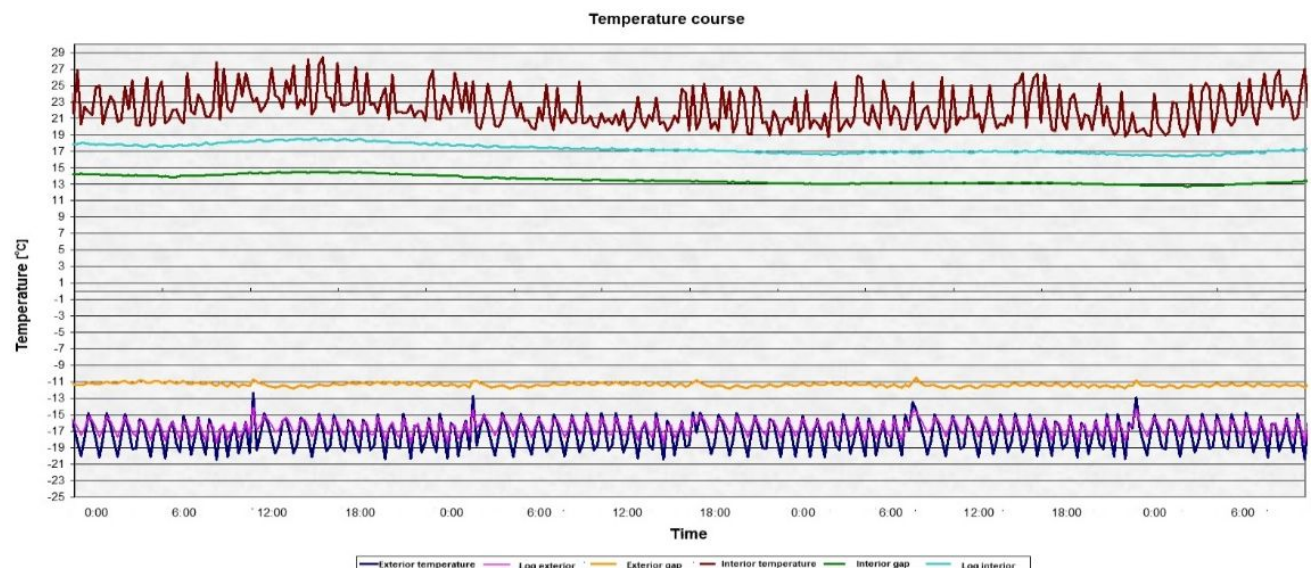

Fig. 5: Results of temperature measurement on both wall sides 


\section{Conclusions}

The project outcome is a finding that currently effective strict thermal technical legislation is met by a shape of joint profile No. 6 , where a cut from the upper log side would need to be made and a grove would need to be made in the bottom part of the log. This construction allows to fill the joint with higher amount of heat insulation, therefore, the highest surface temperature of all modelled variants is reached. However, such type of a groove would be time and cost demanding.

The quality of individual details is paramount for all construction works as well as for wooden structures. Regarding Canadian type log buildings, the outline of a previous log is essential so that the most accurate fit of two following logs is reached. Furthermore, the joint needs to be filled with a sufficient amount of heat insulation and memory tapes properly applied. The object must be properly founded, hydro physical stress of the substructure needs to be dealt with, since it has potential impact on future reconstructions of these structures [6].

Although Canadian-type wooden solid log buildings fail to meet the requirements of the legislation of the Czech Republic, they are considered energy-efficient houses in terms of the whole life-span of the structure, particularly when considering the so-called grey energy stored in construction materials during the process of their production and installation in the building. Specific properties of wood and used natural painting materials give the interior environment unforgettable atmosphere, pleasant warmth and characteristic smell.

This paper has been worked out under the project No. LO1408 "AdMaS UP - Advanced Materials, Structures and Technologies", supported by Ministry of Education, Youth and Sports under the „National Sustainability Programme I".

\section{References}

1. CSN 73 0540-2. Thermal protection of buildings - Part 2: Requirements (Czech Office for Standards, Metrology and Testing, Prague, 2005, 2007, 2011)

2. J. Plachý, V. Petránek, Z. Caha, 11th International Conference Binders and Materials 2013, ICBM 2013, 897, 103-106 (2014)

3. T. Petříček, P. Kacálek, T. Hlavačka, MATEC Web of Conferences, 93, 03007 (2016)

4. P. Kacálek, T. Petříček, R. Smolka, Advanced Materials Research, 899, pp. 58-61 (2014)

5. R. Smolka, J. Sobotka, J. Šulistová, MATEC Web of Conferences, 93, 01009 (2016)

6. J. Sobotka, R. Smolka, MATEC Web of Conferences, 93, 01008 (2016) 